\title{
Estrongiloidíase: Um Diagnóstico a Considerar em Regiões Previamente Endémicas em Portugal
}

\author{
Strongyloidiasis: A Diagnosis to Consider in Previously \\ Endemic Regions in Portugal
}

\author{
Joel PINTO ${ }^{1}$, Paulo ALMEIDA¹, Daniela MEIRELES ${ }^{1}$, Ana ARAÚJO1 \\ Acta Med Port 2021 Jul-Aug;34(7-8):552-556 - https://doi.org/10.20344/amp.12960
}

\begin{abstract}
RESUMO
O Strongyloides stercoralis é um parasita capaz de sobreviver durante décadas num só hospedeiro, graças à sua capacidade de autoinfecção. A estrongiloidíase apresenta uma evolução habitualmente crónica e assintomática, sendo a eosinofilia isolada, as alterações cutâneas e gastrointestinais as manifestações mais frequentes. Entre as décadas de 1910 e 1980, vários casos de estrongiloidíase autóctone de Portugal foram descritos. Os autores apresentam o caso de uma doente com dor abdominal, ascite e eosinofilia marcada. O estudo etiológico excluiu causas frequentes de eosinofilia, sendo confirmado o diagnóstico de estrongiloidíase pela positividade imunoenzimática do anticorpo para Strongyloides stercoralis. Residindo a doente numa região onde foram, no passado, diagnosticados vários casos de estrongiloidíase e na ausência de viagens previas para o estrangeiro, este representa o primeiro caso identificado nas últimas décadas de estrongiloidíase autóctone em Portugal. Os autores alertam para a possibilidade de infeção crónica adquirida em regiões consideradas, previamente, focos de grande endemicidade.
\end{abstract}

Palavras-chave: Estrongiloidíase/diagnóstico; Portugal; Strongyloides stercoralis

\section{ABSTRACT}

Strongyloides stercoralis is a parasite capable of surviving for decades in a single host, due to its ability of auto-infection. Strongyloidiasis usually presents a chronic and asymptomatic evolution, and isolated eosinophilia, cutaneous or gastrointestinal abnormalities are the most frequent findings. Between the 1910s and 1980s, several cases of autochthonous strongyloidiasis in Portugal have been described. We report the case of a patient with abdominal pain, ascites and marked eosinophilia. The diagnostic investigation excluded frequent causes of eosinophilia. The diagnosis of strongyloidiasis was confirmed by immunoenzymatic positivity of the antibody to Strongyloides stercoralis. Since the patient lived in a region where several cases of strongyloidiasis were diagnosed in the past, and given the absence of previous trips abroad, this is the first case identified in recent decades of autochthonous strongyloidiasis in Portugal. The authors point out the possibility of chronic infection acquired in regions previously considered foci of great endemicity.

Keywords: Portugal; Strongyloidiasis/diagnosis; Strongyloides stercoralis

\section{INTRODUÇÃO}

O Strongyloides stercoralis (Ss) tem uma distribuição mundial, estimando-se que entre 30 a 100 milhões de pessoas estejam infetadas. ${ }^{1}$ Frequentemente encontrado em regiões de clima tropical, como a África Subsariana, América do Sul e Este Asiático, pode também estar presente em regiões do Sul da Europa. Presume-se que até à década de 1980, antes da melhoria das condições higiossanitárias, Portugal possuía vários focos endémicos de Ss, particularmente na região Centro. ${ }^{2}$

O contacto da pele com solo contaminado é a forma de contágio, permitindo que as larvas filariformes penetrem na pele do hospedeiro. Atingindo a circulação venosa migram para os pulmões, são expelidas na expetoração e, com a deglutição desta, atingem o tubo digestivo. No intestino delgado as larvas tornam-se fêmeas adultas, que se reproduzem assexuadamente e libertam ovos dentro do intestino, os quais eclodem em larvas rabditiformes, não infetantes, que são então excretadas. Contudo, algumas destas larvas rabditiformes, conseguem evoluir para larvas filiformes ainda dentro do intestino e penetram na sua parede ou na pele perianal, reinfectando o mesmo indivíduo.

Graças à capacidade de autoinfeção, o parasita pode permanecer no mesmo hospedeiro indefinidamente, de forma assintomática em cerca de $60 \%$ dos casos, ${ }^{3}$ ou com períodos de remissão e recorrência. Os sintomas cutâneos e gastrointestinais, como anorexia, vómitos, epigastralgias e diarreia, predominam na estrongiloidíase. A presença de eosinofilia sérica é um achado laboratorial comum e, frequentemente, isolado. ${ }^{4}$

Os autores descrevem um caso de estrongiloidíase, alertando para a possibilidade de existirem doentes portadores de infeção crónica adquirida em regiões do País previamente endémicas.

\section{CASO CLÍNICO}

Doente do sexo feminino de 69 anos, residente num município do distrito de Aveiro, trabalhadora agrícola. Informou não ter história de viagens além-fronteiras, apresentando antecedentes de internamento oito anos antes, por dor abdominal, febre e ascite, com estudo etiológico inconclusivo. Não apresentava outros antecedentes pessoais ou familiares relevantes; negava a toma habitual de medicação. Foi internada por dor abdominal difusa e persistente, com um mês de evolução e progressivamente mais incapacitante,

1. Serviço de Medicina Interna. Centro Hospitalar do Baixo Vouga. Aveiro. Portugal.

$\triangle$ Autor correspondente: Joel Pinto. joelbpinto@hotmail.com

Recebido: 14 de outubro de 2019 - Aceite: 07 de janeiro de 2020 - First published: 21 de setembro de 2020 - Online issue published: 01 de julho de 2021

Copyright $\odot$ Ordem dos Médicos 2021 
apresentando trânsito intestinal mantido, sem diarreia, náuseas, vómitos, anorexia, perda ponderal, febre ou outros sintomas associados. Apresentava-se apirética e hemodinamicamente estável, sem alterações na auscultação cardiopulmonar, abdómen com ruídos hidroaéreos presentes, mole, depressível e difusamente doloroso à palpação profunda, sem sinais de irritação peritoneal nem organomegálias palpáveis. Ao toque retal não se identificavam massas, tendo o dedo de luva fezes castanhas. Do estudo analítico (Tabela 1) destacava-se a presença de leucocitose, eosinofilia $\left(19,79 \times 10^{9} / \mathrm{L}\right)$, discreta elevação da proteína $C$ reativa (PCR) e velocidade de sedimentação, sem citocolestase. As serologias víricas, exame bacteriológico e parasitológico de fezes e serologias para Cryptosporidium, Giardia lamblia e Toxocara canis foram negativas. Na citometria de fluxo de sangue periférico apresentava $43 \%$ de eosinófilos policlonais. A ecografia abdominal revelou a presença de ligeiro derrame peritoneal, confirmado por tomografia computadorizada (Fig.s 1 e 2), que excluiu a presença de sinais de apendicite, diverticulite ou outras alterações tomodensitométricas. Na avaliação analítica seriada (Fig. 3) apresentou redução progressiva da eosinofilia (Tabela 1). Realizou endoscopia digestiva alta que não revelou alterações, sendo a pesquisa de Helicobacter pylori negativa. $\mathrm{Na}$ colonoscopia não apresentava alterações macroscópicas, tendo sido realizadas biópsias da mucosa do cólon direito e esquerdo, cujo estudo histológico revelou alterações morfológicas compatíveis com colite eosinofílica. Na ausência

Tabela 1 - Avaliação analítica realizada durante o internamento. Destaca-se a presença de leucocitose, eosinofilia marcada, elevação da proteína $C$ reativa e velocidade de sedimentação. A citometria de sangue periférico revelou a presença de $43 \%$ de eosinófilos, sem monoclonalidade. O exame bacteriológico e parasitológico das fezes foi negativo, assim como a pesquisa serológica para Cryptosporidium, Giardia lamblia e Toxocara canis. A imunoglobulina E estava dentro dos valores de referência.

\begin{tabular}{|c|c|}
\hline Parâmetro (unidades) & Resultado \\
\hline Hemoglobina (g/dL) & 13,7 \\
\hline Leucócitos (x 10E/L) & $29,1 \uparrow$ \\
\hline Neutrófilos (x 10E/L) & 5,24 \\
\hline Eosinófilos (x 10E/L) & $19,79 \uparrow$ \\
\hline Linfócitos (x 10E/L) & 3,49 \\
\hline Plaquetas (x 10E $\left.{ }^{9} / L\right)$ & 293 \\
\hline Esfregaço de sangue periférico & Eosinofilia marcada. Linfócitos reativos. \\
\hline Proteína C reativa (mg/dL) & $2,16 \uparrow$ \\
\hline Velocidade de sedimentação - $1^{\mathrm{a}}$ hora $(\mathrm{mm})$ & $41 \uparrow$ \\
\hline AST/ALT (U/L) & $24 / 19$ \\
\hline Bilirrubina total (mg/dL) & 0,42 \\
\hline Bilirrubina direta/indireta (mg/dL) & $0,11 / 0,31$ \\
\hline Fosfatase alcalina / GGT (U/L) & $88 / 20$ \\
\hline Amílase / lípase (U/L) & $31 / 31$ \\
\hline Citometria de fluxo de sangue periférico & $43 \%$ de eosinófilos policlonais \\
\hline $\lg A(m g / d L)$ & 386 \\
\hline $\lg \mathrm{G}(\mathrm{mg} / \mathrm{dL})$ & 1300 \\
\hline $\lg M(\mathrm{mg} / \mathrm{dL})$ & 129 \\
\hline $\lg E(U \mathrm{l} / \mathrm{mL})$ & 23 \\
\hline VDRL & Não Reativo \\
\hline VIH - Anticorpo/antigénio & Negativo \\
\hline AgHBs & Negativo \\
\hline AcHBS & Negativo \\
\hline VHC - Anticorpo & Negativo \\
\hline VHE - Anticorpo IgG e IgM & Negativos \\
\hline Parasitológico de fezes (4 amostras) & Negativo \\
\hline Bacteriológico de fezes & Negativo \\
\hline Cryptosporidium - antigénio & Negativo \\
\hline Giardia lamblia - antigénio & Negativo \\
\hline Toxocara canis - anticorpo (UA) & 8 \\
\hline
\end{tabular}

AST: aspartato aminotransferase; ALT: alanina aminotransferase; GGT: gama glutamil transpeptidase; Ig: imunoglobulina; VDRL: venereal disease research laboratory; VIH: vírus da imunodeficiência humana; AgHBs: antigénio de superfície do vírus da hepatite B; AcHBs: anticorpo para o antígeno de superfície da hepatite B; VHC: vírus da hepatite C; VHE: vírus da hepatite E. 


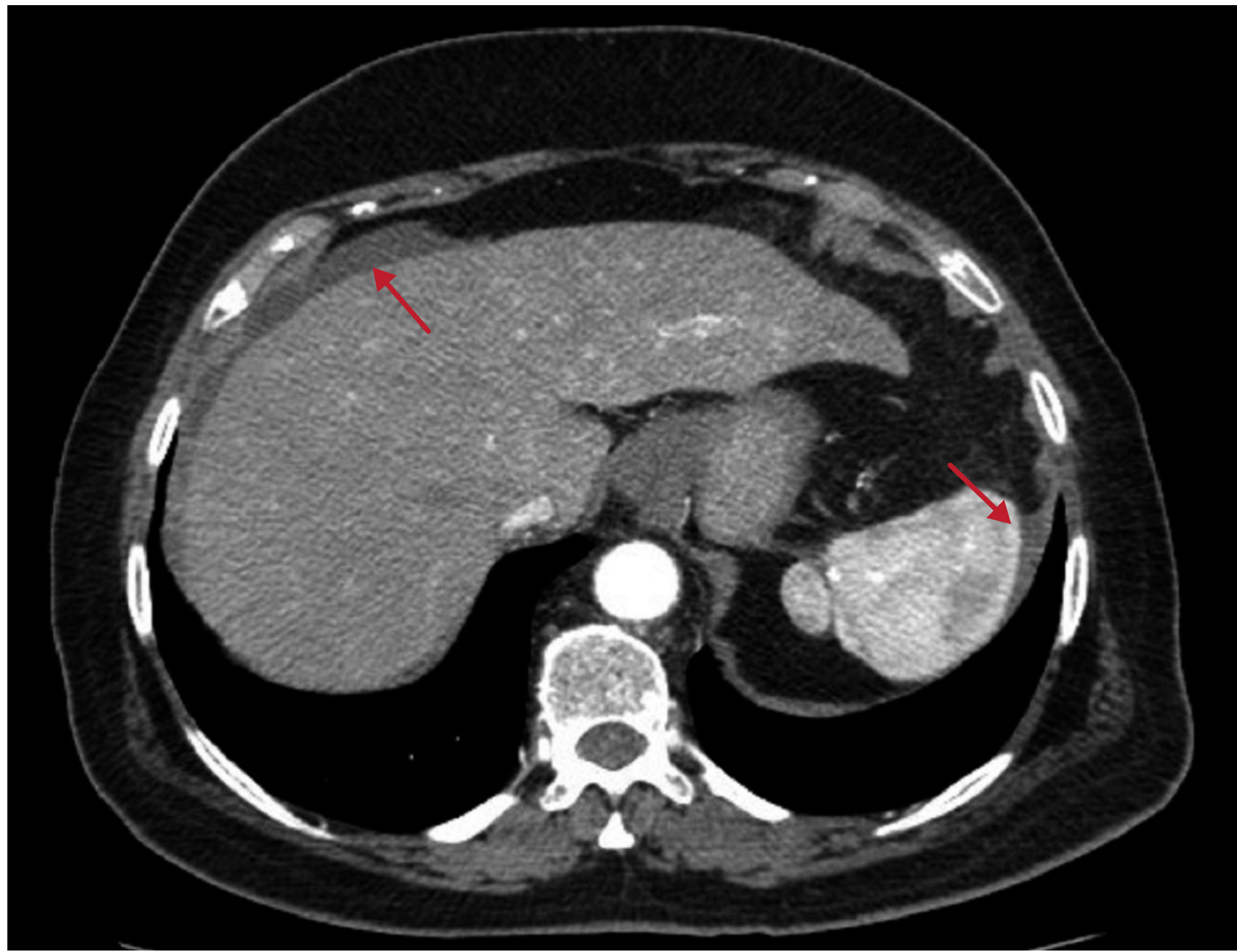

Figura 1 - Derrame peritoneal peri-hepático e peri-esplénico (setas vermelhas)

de diagnóstico estabelecido, foi pesquisado o anticorpo imunoglobulina $\mathrm{G}$ ( $\lg \mathrm{G})$ para Ss por ensaio de imunoabsorção enzimática (ELISA), o qual foi reativo (3,56, valor de referência $<1,00)$. Firmado o diagnóstico de estrongiloidíase, iniciou-se tratamento com ivermectina $(200 \mathrm{mcg} / \mathrm{kg}$ durante dois dias), tendo a doente tido alta assintomática. $\mathrm{Na}$ reavaliação em consulta, um mês após o tratamento, mantinha-se sem queixas gastrointestinais, com normalização dos valores de eosinófilos e parâmetros inflamatórios.

\section{DISCUSSÃO}

Doentes com infeção crónica por Ss representam um desafio diagnóstico, devido à baixa carga parasitária e excreção irregular de larvas. ${ }^{5}$ A eosinofilia, apesar de estar presente em até $75 \%$ dos doentes infetados por Ss, não apresenta uma variação uniforme, encontrando-se frequentemente ausente nos casos mais graves de síndrome de hiperinfeção por Ss (SHS). ${ }^{6}$ Nas infeções parasitárias agudas, o aumento dos eosinófilos é habitualmente acentuado, sendo mais variável nas infeções crónicas. ${ }^{7}$ Estas variações relacionam-se com mecanismos intrínsecos de regulação dos eosinófilos, assim como com o ciclo de vida do parasita, ${ }^{8}$ o que pode explicar a redução progressiva da eosinofilia no caso apresentado, sem terapêutica dirigida instituída.

Na presença de contexto epidemiológico e eosinofilia, a hipótese de estrongiloidíase deve ser considerada, não só em doentes com quadro clínico sugestivo, mas também em doentes imunossuprimidos, pelo risco de desenvolvimento da SHS. ${ }^{4}$ A identificação microscópica das larvas ou ovos de Ss nas fezes é o método gold standard para o diagnóstico, tendo, contudo, uma sensibilidade inferior a $50 \%,{ }^{5}$ o que justifica que, no caso apresentado, o exame parasitológico em amostras seriadas de fezes tenha sido negativo. A pesquisa de anticorpos IgG para Ss por ELISA é, atualmente, considerado um método de investigação mais adequado. ${ }^{4}$ Ainda que a possibilidade de falsos-positivos devido a reatividade cruzada na presença de outras parasitoses fosse anteriormente considerada um problema, novos estudos confirmaram que a sua sensibilidade e especificidade para a identificação de anticorpos para o Ss varia entre $83 \%$ $89 \%$ e $97 \%$, respetivamente. $^{9}$

No caso descrito, a doente tinha previamente sido internada por um quadro clínico semelhante, e ainda que não tenha sido estabelecido um diagnóstico, é possível que tenha sido uma manifestação de estrongiloidíase. Períodos de remissão prolongados, típicos desta parasitose, podem justificar o fato de a doente ter permanecido assintomática 


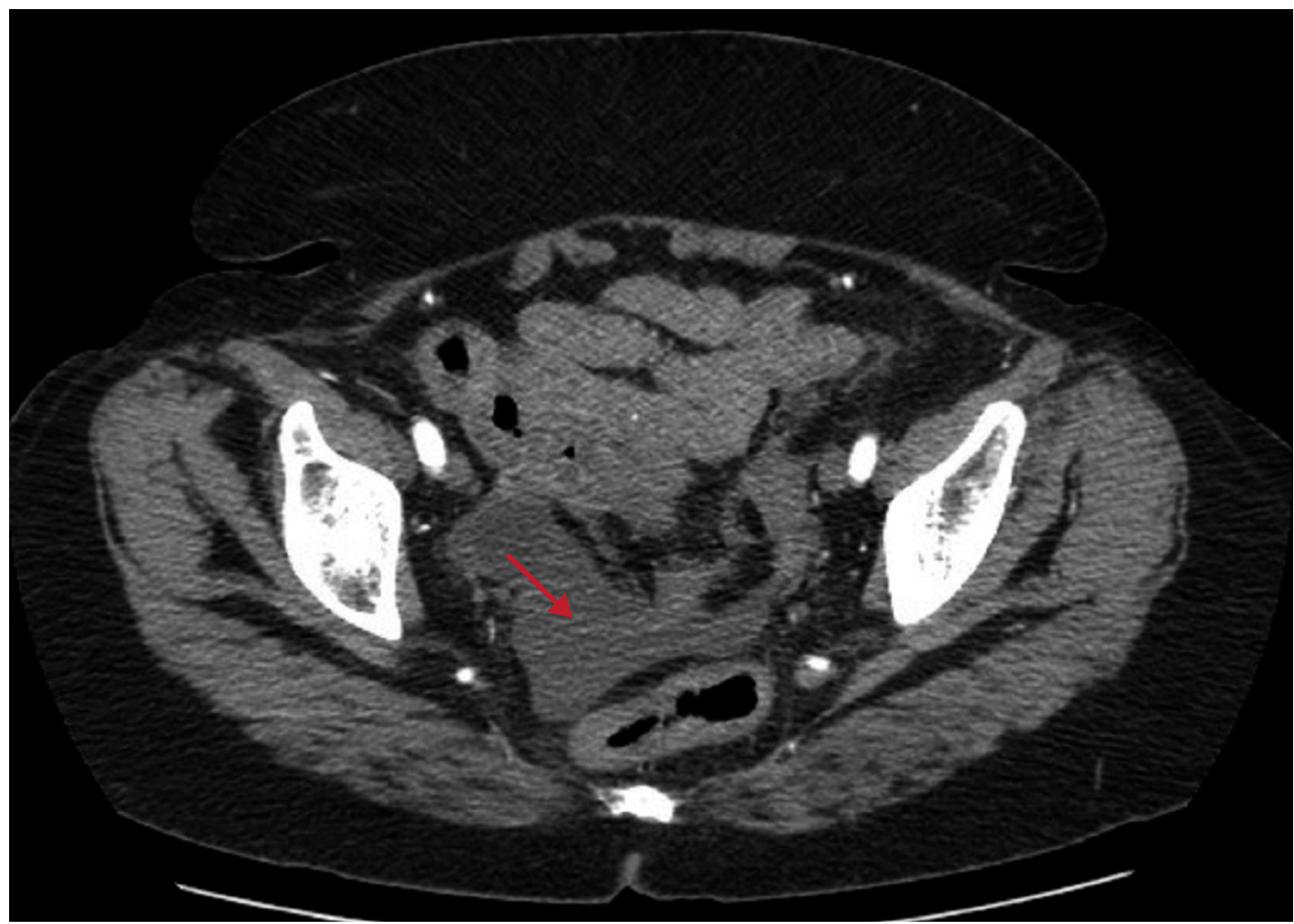

Figura 2 - Derrame peritoneal na escavação pélvica (seta vermelha)

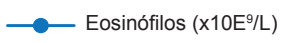

25

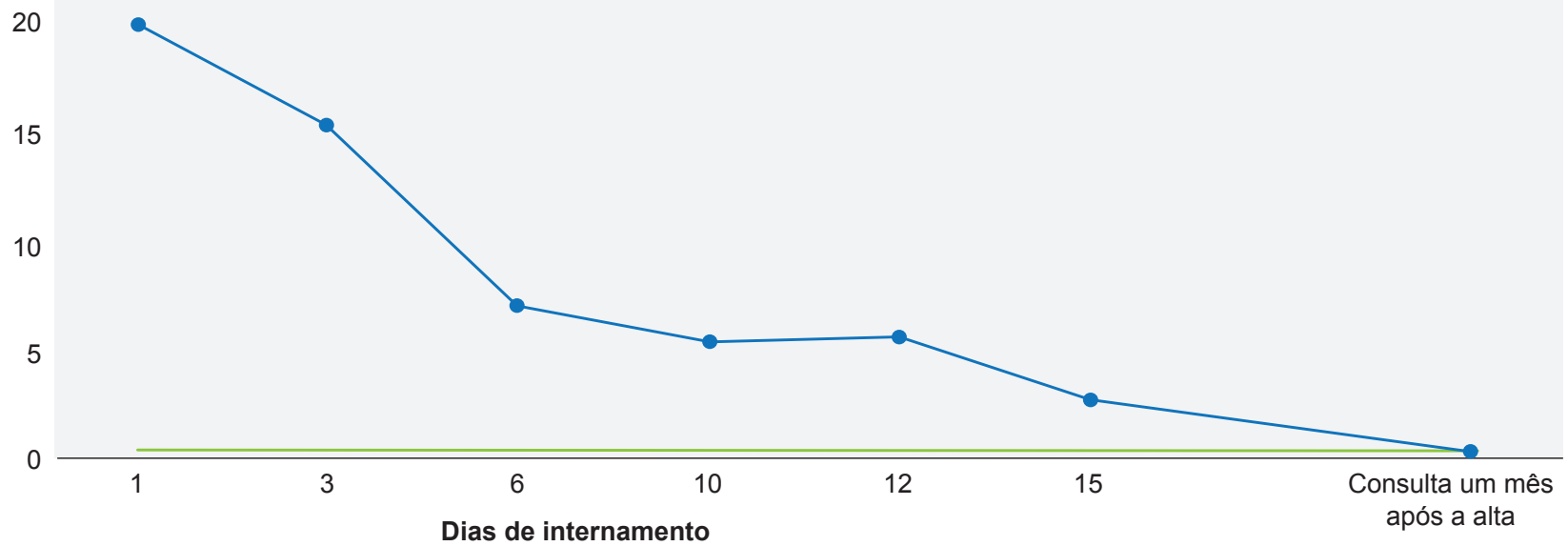

Figura 3 - Evolução da contagem de eosinófilos no sangue periférico

durante oito anos. Apesar de raros, estão descritos casos de gastroenterite eosinofílica e eosinofilia periférica secundárias à infeção por Helicobacter pylori, tendo essa possibilidade sido excluída no caso apresentado. A evolução clínica, a ausência de outras etiologias identificadas para a eosinofilia (doenças alérgicas, fármacos ou outros parasitas) e a resposta à terapêutica fortalecem o diagnóstico, mesmo sem a visualização do parasita.

Para o diagnóstico de estrongiloidíase é fundamental um contexto epidemiológico. A doente natural e residente 
num município do distrito de Aveiro, negava viagens ao estrangeiro. David de Morais publicou uma revisão sobre a ocorrência de estrongiloidíase autóctone de Portugal, ${ }^{2}$ concluindo que, no passado, o baixo nível socioeconómico da população, a inexistência de saneamento básico e a utilização de fezes humanas como fertilizante agrícola potenciaram o desenvolvimento de vários focos endémicos no país, sobretudo na região Centro. Os primeiros casos de estrongiloidíase descritos no país, em 1916, foram identificados em doentes residentes na mesma zona geográfica da nossa doente..$^{10} \mathrm{Admitimos}$ portanto, que é possível que a nossa doente, trabalhadora agrícola desde a infância, tenha, outrora, contraído a infeção por Ss em Portugal.

Este é o primeiro caso identificado, nas últimas décadas, de estrongiloidíase autóctone, em Portugal. Contudo, existe a possibilidade de que existam várias pessoas que, no passado, se tenham contagiado com Ss. Torna-se, portanto, imprescindível, que os médicos portugueses considerem o diagnóstico de infeção crónica por Ss, mesmo em doentes sem história de viagens para países endémicos. Perante doentes nascidos em Portugal até à década de 1980, com clínica de desconforto abdominal recorrente, anorexia ou alterações do transito intestinal e que apresentem eosinofilia periférica, torna-se pertinente a realização de um exame parasitológico de fezes, complementado com a pesquisa sérica do anticorpo imunoglobulina $G(\lg G)$ para Ss. Este alerta ganha particular relevância em casos de patologias imunossupressoras e doenças que careçam de terapêutica citostática ou imunossupressora, pelo potencial risco de SHS, a qual pode ser prevenida com o rastreio e irradicação deste parasita.

\section{REFERÊNCIAS}

1. Krolewiecki A, Nutman TB. Strongyloidiasis: a neglected tropical disease. Infect Dis Clin North Am. 2019;33:135-51.

2. Morais JA. Occurrence of native strongyloidiasis in Portugal retrospective revision. Rev Port Doenças Infecciosas. 2012;8:85-93.

3. Valerio L, Roure S, Fernandez-Rivas G, Basile L, Martinez-Cuevas $\mathrm{O}$, Ballesteros $\mathrm{AL}$, et al. Strongyloides stercoralis, the hidden worm. Epidemiological and clinical characteristics of 70 cases diagnosed in the North Metropolitan Area of Barcelona, Spain, 2003-2012. Trans R Soc Trop Med Hyg. 2013;107:465-70.

4. Greaves D, Coggle S, Pollard C, Aliyu SH, Moore EM. Strongyloides stercoralis infection. BMJ. 2013;347:f4610.

5. Montes M, Sawhney C, Barros N. Strongyloides stercoralis: there but not seen. Curr Opin Infect Dis. 2010;23:500-4.

6. Osiro S, Hamula C, Glaser A, Rana M, Dunn D. A case of strongyloides

\section{CONTRIBUTO DOS AUTORES}

JP: Conceção e desenho do trabalho, aquisição de dados, revisão da literatura, escrita do manuscrito.

PA: Aquisição de dados, revisão da literatura, revisão crítica do texto, escrita e aprovação final do manuscrito.

DM: Desenho do trabalho, revisão crítica e aprovação final do manuscrito.

AA: Supervisão, desenho do trabalho, revisão crítica e aprovação final do manuscrito.

\section{PROTECÇÃO DE PESSOAS E ANIMAIS}

Os autores declaram que os procedimentos seguidos estavam de acordo com os regulamentos estabelecidos pelos responsáveis da Comissão de Investigação Clínica e Ética e de acordo com a Declaração de Helsínquia da Associação Médica Mundial publicada em 2013.

\section{CONFIDENCIALIDADE DOS DADOS}

Os autores declaram ter seguido os protocolos do seu centro de trabalho acerca da publicação de dados.

\section{CONSENTIMENTO DO DOENTE}

Obtido.

\section{CONFLITOS DE INTERESSE}

Os autores declaram a inexistência de conflitos de interesse na realização do presente trabalho.

\section{FONTES DE FINANCIAMENTO}

Este trabalho foi realizado sem contributo de subsídios ou bolsas.

hyperinfection syndrome in the setting of persistent eosinophilia but negative serology. Diagn Microbiol Infect Dis. 2017;88:168-70.

7. Hays R, Thompson F, Esterman A, McDermott R. Strongyloides stercoralis, eosinophilia, and type 2 diabetes mellitus: the predictive value of eosinophilia in the diagnosis of stercoralis infection in an endemic community. Open Forum Infect Dis. 2016;3:ofw029.

8. Klion AD, Nutman TB. The role of eosinophils in host defense against helminth parasites. J Allergy Clin Immunol. 2004;113:30-7.

9. van Doorn HR, Koelewijn R, Hofwegen H, Gilis H, Wetsteyn JC, Wismans PJ, et al. Use of enzyme-linked immunosorbent assay and dipstick assay for detection of strongyloides stercoralis infection in humans. J Clin Microbiol. 2007;45:438-42.

10. Aguiar A, Ramalhão C. Contribuição ao estudo da anguilulose em Portugal. Rev Semiótica Laboratorial. 1916;1:521-54. 